\title{
Chemical change in fish muscle during storage
}

\author{
By N. R. Jones, Torry Research Station, Aberdeen
}

This is a space-restricted condensate of a voluminous technical and research literature. I have been able to make individual reference principally to recent reviews and certain papers that can lead the reader to earlier work. Heen \& Kreuzer ( I962) have edited a recent compilation covering many of the subjects touched upon.

Chemical change that occurs between the catching of a fish and its preparation for the table is determined by the processes to which the fish may be subjected and by the intrinsic properties of the fish itself. Frequently, the second of these considerations governs the first. For instance, the removal of fat during processing is a prerequisite for preparing dried 'fatty' fish with reasonably satisfactory storage characteristics. The following sections touch upon the common conditions of storage.

\section{Chill storage}

The storage life of most fish caught by British vessels is prolonged by packing it in crushed ice. Ashore, chilling may be maintained by mechanical refrigeration, but ice is used frequently throughout storage to the point of sale to the housewife. Chilling in refrigerated sea-water is successful for some species (Tarr, 1957). Usually, fish are eviscerated as soon as possible after catching: otherwise the gut enzymes of most species attack the flesh by proteolysis (Siebert, Malortie \& Beyer, 1962).

In eviscerated fish, muscle undergoes considerable chemical change from the activities of the tissue enzymes (Jones, I962a). Glycolysis can produce sequential rises and falls in hexose phosphate concentration, and related changes in other phosphorylated intermediates, pyruvic acid and lactic acid can result in a fall in $\mathrm{pH}$. Maintenance of adenosine-5'-triphosphate (ATP) concentrations (Tomlinson \& Geiger, 1962) may be a temporary result of such reactions in some circumstances but eventually ATP is degraded via inosine- 5 '-monophosphate (IMP) to hypoxanthine (Kassemsarn, Sanz Perez, Murray \& Jones, I963). Failure of the ATP supply disrupts a number of biosynthetic mechanisms in the tissue. As other systems that break down constituents of complex structure remain active in the muscle, many simple compounds such as amino acids tend to accumulate.

After about 6 days, the processes of bacterial spoilage become superimposed progressively upon those of autolysis. Early workers concentrated on bacterial proteolysis and the reduction of trimethylamine oxide, which are major attributes of spoilage. More recently, interest has centred upon the production of individual volatile constituents, such as skatole, lower fatty acids, 'carbonyls', mercaptans, pyridinelike compounds and amines other than the methylamines (Shewan, i 962).

Some work has been carried out on the manner in which bacterial spoilage and autolysis are related. It is apparent that autolysis can provide predigested nutrients for the spoilage microflora and that the $\mathrm{pH}$ of the muscle controls its proliferation. 
With the development of antibiotic processes of chill preservation, such as incorporating tetracyclines in preservative ice or packing fillets in vacuo, such interrelationships are of increasing interest. It has been established, for instance, that the microfloras selected by different treatments can utilize technologically important products of autolytic change to different degrees (Sanz Perez \& Jones, 1962).

In all chill storage involving the direct contact of flesh with melting ice, considerable losses of some constituents may result from leaching.

\section{Frozen storage}

A number of economically important chemical reactions are associated with the storage of frozen fish. In general, rates of reaction are highest just below the freezing point of the muscle (often in the region of $-4^{\circ}$ ). Under such conditions, rates are frequently higher than those occurring at just above the freezing point. This is a result of the concentration of catalytic salts and reactants that attends the effective removal of water. Below about $-4^{\circ}$, rates fall with temperature.

Frozen fish sometimes toughens, and loses water when it is thawed. The chemical bases of the reactions giving rise to these deteriorations have not been established with certainty, but there are good grounds for supposing that the physical effects are end-products of a 'denaturing' process in which the proteins undergo 'configurational change in the direction of a less-ordered or unfolded structure' (Connell, I962). Experiments with model systems have demonstrated polymerization reactions between myosin molecules following upon initial denaturation. There appears to be good correlation between the tendencies of myosins from different species to undergo such reactions and the storage properties of the intact muscles.

Recently a causative relationship between lipid hydrolysis and protein denaturation has been postulated (cf. Dyer \& Fraser, 1959). These claims received some support from a study (King, Anderson \& Steinberg, 1962) which demonstrated a catalysis of myosin aggregation by free fatty acids in model systems. However, Olley, Pirie \& Watson (1962) showed that the absolute concentrations of free fatty acids liberated enzymically in frozen fish cannot be the determining factor in denaturation. Possibly, both the relative stabilities of myosins and the concentrations of any catalysts may be important.

Enzymic reactions in frozen fish involving a number of other metabolites have been reported (see, e.g., Partmann, 196I). Glycolysis, nucleotide degradation and proteolysis have been demonstrated at temperatures down to $-30^{\circ}$. The greater stability of muscle proteins frozen before rigor as compared with after rigor (Love, ig62) may well reflect such changes.

In fatty species such as herring, the most serious cause of deterioration is oxidation (cf. Olcott, 1962). Fish lipids are characterized by a high degree of unsaturation in the form of multiple double bonds in the fatty acids. These are susceptible to attack by molecular oxygen. Oxidation proceeds by a free radical mechanism involving chain reactions. An induction phase is followed by accelerating rates of oxygen absorption, with the formation of hydroperoxides, odorous compounds of low molecular weight and polymerized products. Many heavy metals accelerate 
oxidation so that the possible role of haem pigments in dark muscle, which is particularly susceptible to oxidation, has been of considerable interest. At the present time, the question does not appear to have been resolved conclusively.

Oxidation may be inhibited or slowed in practice by applying a surface 'glaze' of ice to limit access of air to the tissue. This also limits 'freezer burn', a discoloration associated with surface desiccation. The use of antioxidants and chelating agents has not been so successful under practical conditions.

A 'rusting' or 'browning' discoloration develops occasionally in frozen fish. This effect is not understood completely, but reactions of compounds possessing carbonyl, or potential carbonyl, groupings appear to be implicated. Such compounds can be present as natural constituents of the muscle, such as free sugars and glycolytic intermediates. Or they can derive from the processes of fat oxidation. They readily undergo reactions with amino compounds of the flesh in model systems. There is evidence also that reactions involving unsaturated fat can produce discolorations in the absence of amino constituents.

\section{Storage of dehydrated fish}

Dehydration processes vary widely, ranging from sun drying to the accelerated freeze drying of non-fatty species and the solvent-extraction procedures used successfully for the production of fish flours. The diversity of starting materials and methods can predispose products to different types of storage change.

In 'fatty' fish from which lipid has not been removed, or has been extracted incompletely, autocatalytic oxidative reactions can lead to the development of objectionable flavours and discoloration such as can occur in oxidizing frozen material (see p. 173). These oxidative changes can be disastrous, as the heat generated results in spontaneous combustion on occasion. Overheating can damage the muscle proteins seriously under less extreme conditions (Olcott, I 962). In non-fatty species, conditions of processing or packaging that allow free access of atmospheric oxygen may predispose the oxidation of phospholipid with a development of 'off' flavour.

In dehydrated material much discoloration results from sugar-amino-compound reactions (Jones, I $962 b$ ). Such reactions are catalysed by heavy metals. Serious discoloration problems can arise, for instance, when copper contaminates equipment or salt used in processing.

Toughness that develops in dehydrated fish is similar in some respects to that of frozen material. However, with the exceptions of the products of the gentlest processing operations, it seems likely that only a relatively small proportion of any damage to the proteins will occur during storage (cf. Connell, I962). When the condition of the muscle before processing is such that a suitable carbohydrate environment is available, considerable protein-sugar reaction can occur even at low temperatures. Excessive heating results in further extensive reaction within the proteins themselves.

Enzymic activity can be maintained in dehydrated material (Hunt \& Matheson, I958). 


\section{Storage of canned fish}

Very little information is available on the chemistry of storage changes in canned fish, although it is well established that both flavour and texture alter. The decomposition of trimethylamine oxide and reactions involving carbonyl compounds may be implicated (Ronold \& Jakobsen, I947; R. B. Hughes, 1963, personal communication).

\section{Storage of other fish products}

Deteriorative changes occurring during the storage of smoked fish have not been elucidated. They appear to be similar to those of unsmoked material.

The inherent enzymic activity of the fish plays a considerable part in the maturation of semi-preserves, such as those prepared from herring in Europe, and during the preparation and storage of the fermented fish products popular in south-east Asia (cf. Amano, I 962). Bacterial activity contributes to the flavour of the latter.

\section{Nutritional implications of storage changes}

Many of the reactions involving constituents of low molecular weight in fish products affect acceptability. Flavour changes are particularly important in this respect. Lipid oxidation in frozen fish is responsible for the development of rancidity, for instance; and, in chill-stored fish, the autolytic degradation of nucleotide substitutes a bitter-tasting compound for one with a pleasant meaty flavour (Jones, I96r).

Textural changes, resulting from the reactions of proteins, can also lower the acceptability of products. A more serious result of some protein reactions is loss of biological value (cf. Carpenter \& Lea, 1962).

Fat oxidation can produce undesirable effects additional to rancidity and discoloration, and the direct loss of nutrient. Hydroperoxides have been shown to injure the intestinal wall on ingestion (Andrews, Griffith, Mead \& Stein, 1960). Co-oxidative reactions can lead to the destruction of vitamin A, other carotenoids and vitamin $\mathrm{E}$.

Significant losses of other vitamins can occur during processing and storage. Concentrations of $\mathrm{B}$ vitamins fall, for instance, during the chill storage of shrimps (Novak, Fieger \& Bailey, 1956), and the well-known activity of the thiaminase of fish tissues (Harris, 195 I.) has resulted in economic losses to the fur-farming industry. Some loss of B vitamins occurs during frozen storage (Bramsnaes, I962) but the overall retention is good. Losses in canned material appear to be associated mainly with processing: canned mackerel and tunny retained most of their riboflavin, nicotinic acid and vitamin $B_{12}$ during 6 months' storage at room temperature, but thiamine concentrations fell considerably (Komata, Hashimoto \& Mori, 1956).

This paper was prepared as part of the programme of the Department of Scientific and Industrial Research. I am indebted to my colleagues at the Torry Research Station for helpful advice and criticism during its preparation. 


\section{REFERENCES}

Amano, K. (1962). In Fish in Nutrition, p. 180. [E. Heen and R. Kreuzer, editors.] London: Fishing News (Books).

Andrews, J. S., Griffith, W. H., Mead, J. F. \& Stein, R. A. (1960). F. Nutr. 7o, I 99.

Bramsnaes, F. (1962). In Fish in Nutrition, p. 153. [E. Heen and R. Kreuzer, editors.] London: Fishing News (Books).

Carpenter, K. J. \& Lea, C. H. (1962). In Fish in Nutrition, p. 3 ro. [E. Heen and R. Kreuzer, editors.] London: Fishing News (Books).

Conneil, J. J. (1962). In Recent Advances in Food Science. Vol. 1, p. I36. [J. Hawthorn and J. M. Leitch, editors.] London: Butterworths.

Dyer, W. J. \& Fraser, D. I. (1959). F. Fish. Res. Bd Can. 16, 43.

Harris, R. S. (I95 I). In The Enzymes. Vol. I, Part 2, p. I 186 . [J. B. Sumner and K. Myrback, editors.] New York: Academic Press Inc.

Heen, E. \& Kreuzer, R. (editors) (1962). Fish in Nutrition. London: Fishing News (Books).

Hunt, S. M. V. \& Matheson, N. A. (1958). Nature, Lond., 18r, 472.

Jones, N. R. (1961). In Proceedings Flavor Chemistry Symposium, p. 6r. Camden, N.J.: Campbell Soup Co.

Jones, N. R. (1962a). In Recent Advances in Food Science. Vol. I, p. 151. [J. Hawthorn and J. M. Leitch, editors.] London: Butterworths.

Jones, N. R. (1962b). In Recent Advances in Food Science. Vol. 2, p. 74. [J. Hawthorn and J. M. Leitch, editors.] London: Butterworths.

Kassemsarn, B.-O., Sanz Perez, B., Murray, J. \& Jones, N. R. (Ig63). F. Fd Sci. 28, 28.

King, F., Anderson, M. \& Steinberg, M. (1962). In Fish in Nutrition, p. I48. [E. Heen and R. Kreuzer, editors.] London: Fishing News (Books).

Komata, Y., Hashimoto, Y. \& Mori, T. (1956). Bull. fap. Soc. sci. Fish. 21, 1236.

Love, R. M. (1962). f̈. Sci. Fd Agric. 13, 534.

Novak, A. F., Fieger, E. A. \& Bailey, M. E. (1956). Quick Froz. Fds, 18, no. 12, p. 64.

Olcott, H. S. (r962). In Fish in Nutrition, p. 112. [E. Heen and R. Kreuzer, editors.] London: Fishing News (Books).

Olley, J., Pirie, R. \& Watson, H. (1962). J. Sci. Fd Agric. 13, 50 r.

Partmann, W. (196r). Z. Ernährungsw. 2, 70.

Ronold, O. A. \& Jakobsen, F. (1947). F. Soc. chem. Ind., Lond., 66, I60.

Sanz Perez, B. \& Jones, N. R. (1962). F. Fd Sci. 27, 69.

Shewan, J. M. (1962). In Recent Advances in Food Science. Vol, 1, p. 167. [J. Hawthorn and J. M. Leitch, editors.] London: Butterworths.

Siebert, G., Malortie, R. V. \& Beyer, R. (I962). Arch. Fischereiwiss. 13, 21.

Tarr, H. L. A. (1957). Arch. Fischereiziss. 8, Suppl. I, p. 9.

Tomlinson, N. \& Geiger, S. E. (1962). J. Fish. Res. Bd Can. 19, 997.

\section{Flavour in potatoes}

\section{By R. Self and T. SwaIN, Low Temperature Research Station, Downing Street, Cambridge}

The intrinsic nutritional quality of foods counts for little if they are not acceptable to the consumer. The reasons why certain foods are more acceptable than others are extremely complex, but one of the undoubtedly more important factors is flavour. Like any other aspect of quality, the most desirable flavour for any given food will depend on a number of considerations, but in any one country there will be a norm acceptable to the majority of consumers. Changes in the flavour of a food due to genetic factors, to variations in the conditions of growth and storage, or to manufacturing processes are therefore obviously of great importance in determining the acceptability of a food. In this paper methods are described for studying such changes in the volatile substances responsible for the aroma of cooked potatoes, 